\title{
Varieties of Living Things: Life at the Intersection of Lineage and Metabolism
}

\author{
John Dupré $e^{\S}$ and Maureen A. O’Malley ${ }^{\S}$
}

\begin{abstract}
We address three fundamental questions: What does it mean for an entity to be living? What is the role of inter-organismic collaboration in evolution? What is a biological individual? Our central argument is that life arises when lineage-forming entities collaborate in metabolism. By conceiving of metabolism as a collaborative process performed by functional wholes, which are associations of a variety of lineage-forming entities, we avoid the standard tension between reproduction and metabolism in discussions of life - a tension particularly evident in discussions of whether viruses are alive. Our perspective assumes no sharp distinction between life and non-life, and does not equate life exclusively with cellular or organismal status. We reach this conclusion through an analysis of the capabilities of a spectrum of biological entities, in which we include the pivotal case of viruses as well as prions, plasmids, organelles, intracellular and extracellular symbionts, unicellular and multicellular life-forms. The usual criterion for classifying many of the entities of our continuum as non-living is autonomy. This emphasis on autonomy is problematic, however, because even paradigmatic biological individuals, such as large animals, are dependent on symbiotic associations with many other organisms. These composite individuals constitute the metabolic wholes on which selection acts. Finally, our account treats cooperation and competition not as polar opposites but as points on a continuum of collaboration. We suggest that competitive relations are a transitional state, with multi-lineage metabolic wholes eventually outcompeting selfish competitors, and that this process sometimes leads to the emergence of new types or levels of wholes. Our view of life as a continuum of variably structured collaborative systems leaves open the possibility that a variety of forms of organized matter - from chemical systems to ecosystems - might be usefully understood as living entities.
\end{abstract}

\section{KEYWORDS}

Autonomy $\bullet$ Collaboration $\bullet$ Lineage formation $\bullet$ Living $\bullet$ Metabolic whole $\bullet$ Non-living

It would seem that 60 years after Erwin Schrödinger wrote his book 'What is Life?' we should be able to answer the question. However, Nature never ceases to challenge the limits of our imagination.

- M. Y. Galperin $(2005,149)$

This essay will not attempt to provide a definition that answers Schrödinger's question. We shall instead address it by describing a spectrum of biological entities that illustrates why no sharp dividing line between living and non-living things is likely to be useful. The more positive goal of these reflections will be to offer a

$\S$ Egenis, University of Exeter, St Germans Road, Exeter, EX4 4PJ, UK

E-mail: m.a.o'malley@exeter.ac.uk

Received 5 May 2009; Accepted 17 August 2009 
flexible view of life that does in fact make good sense of why particular organizations of matter can be described as living. By identifying the different capacities exhibited by the various entities constituting our spectrum, especially problem cases such as viruses, we hope to address at least some of the issues that lie behind Schrödinger's question and its many earlier precursors and subsequent echoes. Such concerns have been raised in a striking way by recent attempts under the rubric of 'synthetic biology' to synthesize life from basic chemical building blocks.

In this paper we shall highlight a tension in standard discussions of characteristics of life, which tend to prioritize one or other of two fundamental but very different features of living things: the capacity to form lineages by replication and the capacity to exist as metabolically self-sustaining wholes. We suggest that this tension can best be resolved by seeing life as something that arises only at the intersection of these two features: matter is living when lineages are involved - directly or indirectly - in metabolic processes. But also crucial to our argument and, we suggest, to many of the difficulties that have confronted attempts to comprehend life, is the observation that the entities that form lineages are not always, or even usually, the same as those that form metabolic wholes. Metabolism, the transformative biochemical reactions that sustain life processes, we shall argue to be a collaborative affair. Life, we claim, is typically found at the collaborative intersections of many lineages, and we even suggest that collaboration should be seen as a central characteristic of living matter - a claim that also has implications for how we understand the origins of life. Further corollaries of this non-coincidence of parts of lineages with metabolic wholes are, first, that we cannot assume the identification of living things with organisms (at least as standardly conceived), and nor, second, can we assert traditional organisms to be 'the' biological individuals on which selection operates.

\section{Collaboration and the diversity of life}

The collaborative nature of living entities and processes is our essential starting point. Darwin's theory of natural selection has, quite appropriately, focused a great deal of theoretical interest on questions of competition. This focus, however, has had the less salutary consequence of diverting attention from the equally important topic of cooperation and has culminated in the assumption that altruism, understood as the conferral of a benefit by one biological entity on another, is a profound theoretical problem. Although this is generally seen as a problem pertaining to organisms, a similar argument has notoriously been applied to the topic of genes. Richard Dawkins (1976) made famous the idea that genes are fundamentally selfish entities in competition with one another. From this point of view, it is truly remarkable that the whole consortium of genes in an organism's genome can nevertheless manage to collaborate on a task as momentous as development.

In this paper we place selfishness in a wider context and emphasize the broader perspective of life as a collaborative enterprise. We are not arguing that interpretations of selfishness are invalid but that, at best, they can only provide a limited perspective on life and evolution. Rather than reducing cooperation to selfishness, we suggest selfishness and cooperation might better be understood within a framework of collaboration. By collaboration, we mean interactions between components of a system that lead to different degrees of stability, maintenance or transformation of that system. As in scientific collaborations, there may be some strongly selfish interests involved in such interactions (Hull 1988) but these selfish activities can only operate in a collaborative context. Defecting from collaboration is only possible if collaboration is the general default.

In every domain of organismal life, there are extensive sets of organisms that are problematic for standard evolutionary understandings of selfish individuals (Roughgarden 2009). Shared interests can lead to highly cooperative 'team' behavior, described by Joan Roughgarden as 'cooperative teamwork' (2009: 13). Evolutionary payoffs for such team members may not be equal, but are distributed across the whole team. Collaboration, however, may also include the 'mere' coincidence of individual interests, and it is often in the interest of any individual to collaborate - at least to some extent. Collaboration from this point of view covers a range of interactive processes that may include both cooperative and competitive activities. At one end of this continuum the goals of participants may be completely aligned, while at the other end of the 
continuum, relationships may be largely or wholly hostile. We will try particularly to understand the evolutionary persistence of apparently 'parasitic' or selfish interactions between organisms, and the nature of the entities formed by what are usually conceived as separate biological individuals.

One aspect of collaboration is merely interactive combination. Thus atoms combine to produce molecules, and the latter have properties that are not found in any of the atoms of which they are composed. But certainly more than this is required to count as collaboration in the sense we are elaborating. In common with most who have considered the question of how living entities are constituted, we assume that there is one necessary condition for being a living thing that most combinations of atoms and molecules lack: the ability to reproduce. Though we take this to be a necessary condition, it is less obvious that it is sufficient. Living entities have also to be understood in relation to their capacity to sustain themselves through biochemical transformations. Metabolism in our account can be engaged in autonomously (this is the usual understanding) or collaboratively, through interactions with other biological entities. At any rate, as the microbial and microbe-like entities that we shall describe below illustrate, a very diverse group of things both reproduce and participate in metabolic systems.

Our empirically informed investigation of living matter will not be based on the animal, fungi or plant life that has been the main concern of philosophers and scientists concerned with these issues; nobody questions the status of these as living things, and the problem is only one of deciding which of their characteristics confer the status of living on them. We shall focus instead on the realm loosely referred to as microbial, which includes some entities only contentiously afforded living status. Microbes are a group of organisms biologically and conceptually diverse to the point of incoherence, but then so are the macroorganisms or macrobes that loom large in most perspectives on life (O'Malley and Dupré 2007). The category of microbes includes at least protists (unicellular eukaryotes, which have membrane-bound nuclei and other organelles), prokaryotes (which don't have such compartments but are highly organized in other ways), and viruses.

Viruses are the biological objects that are the pivot of our discussion because many biologists deny that they are living organisms. In fact, they are frequently considered to be test cases for the boundary between life and non-life, organism and non-organism, and biology and chemistry (e.g., Stanley 1957; Wimmer 2006). They are most often assigned to the second of each of these pairs of categories. Viruses are often deemed not to be alive on the grounds that they cannot reproduce themselves autonomously, and nor can they metabolize. They can, however, carry out such biologically impressive activities as entering cells, coopting the transcription and translation machinery of the cell, and picking up and moving about DNA from the organisms with which they interact. And by exploiting or collaborating with cellular organisms in these ways, they very effectively reproduce themselves and have no need of autonomous metabolism.

Thinking about viruses and their relegation to the realms of non-living and non-organismal entities necessitates a consideration of whether organism and living entity are identical categories, and whether a minimal account of life has to begin with cells. Such thoughts then invite further reflection on other biological entities that seem to have some autonomy but are almost never described as living organisms. Joshua Lederberg, a pioneer in molecular biology who first formulated the term 'plasmid' (Grote 2008), places these biological entities in the same category of 'symbiotic organisms' as he does mitochondria and chloroplasts. For him, they comprise part of 'the organic whole' (Lederberg 1952, 403). He argues more broadly that any scheme of life has to work out where to place prions, plasmids, integrons (gene capture and integration systems) and transposons - mobile genetic elements in a genome, sometimes called jumping genes' (Lederberg 1998). (1)

We will take our cue from Lederberg and start our examination of life with a discussion of some of the biological entities that inhabit this grey area between living and non-living, specifically prions, plasmids, organelles, endosymbionts and reduced extracellular symbionts. As we move along this continuum of biological organization to entities whose living status is never questioned (micro- and macroorganisms), we will investigate whether these instances of entities possess some of the most frequently cited life-endowing characteristics, such as spatial boundedness, reproduction, metabolism and evolvability, and how our criterion, collaborativity, relates to these characteristics. We will also argue that our account of cellular and sub-cellular entities fits very well with origin-of-life scenarios that stress chemical collaboration and community. Our bottom-up perspective, starting at the microscopic level of biology, rather than top-down 
from its most complex and undisputed exemplars, will suggest that much standard thinking is based on quite restricted and even covertly normative conceptions of what life is. This perspective will ultimately challenge the view that entities such as viruses are not alive and that the minimal definition of life must be cellular.

\section{A spectrum of biological entities}

\subsection{Prions}

Once thought of as 'slow viruses', prions are now commonly understood to be self-propagating proteins that are able to convert normal proteins of the same type into the pathogenic prion conformation (Weissmann 2004; Prusiner 1998; Soto and Saborio 2001). (2) They have a life cycle from induction (3) to self-perpetuation (the conversion of another protein). Prions are very robust and persisting entities, because their conformation makes them highly resistant to inactivation by chemical, heat and irradiation treatments.

The central oddity of prions is that they propagate autocatalytically in a protein-only form, without DNA involvement. (4) For this reason, they are frequently referred to as protein-based genes (Wickner et al. 2004; Uptain and Lindquist 2002). Although best known as non-Mendelian hereditary elements (5) in diseased sheep, cattle and humans, prions exist in unicellular organisms too. Yeast and other fungal prions share no amino acid sequence similarities with mammal prions, and they function and are transmitted very differently (Bousset and Melki 2002; Uptain and Lindquist 2002; Weissmann et al. 2002). Nevertheless, experimental work on yeast prions has provided deep insights into conformational change in proteins and their transmission (Wickner et al. 2007).

The Modern Synthesis does not cope well with prions, and this has led some commentators to propose that a more comprehensive theory of inheritance is needed for prions to be properly understood evolutionarily (Jablonka and Lamb 2005; Chernoff 2001). The prion-forming potential of the implicated yeast proteins is evolutionarily conserved, implying that it is adaptive (Chernoff et al. 2000). Diverse functions have been identified or proposed for prions in a range of taxa. There is some evidence that prions are associated with epigenetically enabling yeast cells to cope with fluctuating environments, and that they play a role in memory formation in sea slugs (Shorter and Lindquist 2005). The non-pathogenic isoform of human prion proteins (the functions of which are still largely mysterious) is linked to the prevention of Alzheimer's disease (Parkin et al. 2007).

These capabilities and characteristics do not give a ready answer to the question of whether the selfpropagational status of prions gives them the status of being alive. Although genes are frequently given a special 'informational' role in accounts of heredity (e.g., Hood and Galas 2003), the conferral of a similar status on proteins - as information-bearing molecules - does not simultaneously make them into living entities. Genes and proteins are not classified as alive in their own rights, (6) despite the wide-spread 'selfish DNA' thesis that seems to confer autonomy on nucleotides (Doolittle and Sapienza 1980; Orgel and Crick 1980), and despite the recognition of the absolute centrality of enzymes to life processes (Kornberg 1989; Lezon et al. 2006).

Prions exhibit collaborative behaviors that benefit themselves, as a class of protein isoforms, as well as their hosts. When low amounts of the non-pathogenic isoform are produced, the prion conversion process halts, and when high amounts of the former are produced, it may stimulate spontaneous prion formation in the previously prion-free cell (Chernoff et al. 2000; Derkatch et al. 2001). Prion propagation in yeast requires the involvement of chaperon proteins. Moreover, prions in yeast are associated with greater adaptability in yeast because they increase protein variation - a factor that may prove advantageous in variable environments and eventually be genetically assimilated (True and Lindquist, 2000; Pál 2001; Masel and Bergman 2003). It is these abilities to interact with biological processes at different levels of organization that presumably explain evolutionarily the prion's powers of persistence.

\subsection{Plasmids}

Plasmids are small, stably inherited and self-replicating molecules of DNA (sometimes RNA) that are independent of the chromosomal DNA in bacterial, archaeal and eukaryotic cells. Plasmids are prolific and 
diverse; they may be larger than some prokaryote genomes (del Solar et al. 1998). Many are mobile genetic elements that direct their own transmission to new host cells during conjugation (the unicellular equivalent of sex), thereby spreading themselves to closely related and evolutionarily distant prokaryotes (Thomas 2000; 2006; Sørensen et al. 2005). They are then transmitted vertically, from mother to daughter cells.

Plasmids have a two-stage life cycle of establishment and proliferation followed by a steady state that matches the cell cycle (del Solar and Espinosa 2000). Neighbouring plasmid-free cells are often killed by plasmids, and this leads to a very high rate of successful infection (Gerdes et al. 1986; Eberhard 1990; Bingle and Thomas 2001). The complexities of plasmid characteristics have led some biologists to describe them as 'subcellular organisms' or endosymbionts with distinct autonomy from their host (Perlin 2002, 508). Because of their many talents, plasmids have become a mainstay of laboratory genetic manipulation as vectors of gene transfer.

Plasmids are often described as selfish in the same way that other genetic elements are because they encode genes that are not essential for the host and may impose fitness costs (Kado 1998). Importantly, however, they also play more cooperative roles in cells (Wegrzyn 2005). Plasmids often encode and express genes of a variety of functions apart from those for their own mobility and replication, such as antibiotic resistance, virulence, environmental protection (including biofilm formation), DNA repair and supplementary metabolic pathways (Barton et al. 1995; Ghigo 2001). They can thus be seen as collaborative elements that enhance the functionality and adaptiveness of their host cells. The fact that these features favour plasmid survival has allowed these phenomena to be interpreted as instances of selfishness (Kado 1998), but in our framework they could equally well be interpreted as examples of (sometimes mutualistic) collaboration.

\subsection{Organelles}

Organelles are diverse membrane-bound compartments in eukaryote cells. (7) They carry out highly specialized biochemical functions and communicate between themselves to achieve this division of labour (Lowe and Barr 2007; Munro 2004). Major organelles include mitochondria and plastids (including chloroplasts, the organelles enabling photosynthesis in plants), as well as peroxisomes (compartments involved in metabolic activities that include the oxidative metabolism of fatty acids and the breakdown of hydrogen peroxide) Golgi complexes and endoplasmic reticula. Apart from the nucleus, most organelles are primarily involved in energy generation, transport and storage. They are often highly dynamic, mobile structures that react to relevant features of the environment to maintain cell function (Cutler and Ehrhardt 2000; Braun and Schleif 2007; Collings et al. 2000).

Organelles are often considered to be 'autonomous structures' because of their semi-independent inheritance strategies (Warren and Wickner 1996, 398; Nunnari and Walter 1996). Organelles reproduce within cells and a complete set is passed on to the daughter cells during cell division. However, because most membranes have to be inherited from pre-existing membranes and are usually not constructed de novo, (8) organelles are templated from pre-existing organelles. They self-assemble on the basis of the information their membranes carry about membrane polarity, type and location (Cavalier-Smith 2000; Lowe and Barr 2007).

Two of the most evolutionarily fascinating organelles were once free-living bacteria. Mitochondria and plastids functioned first as intracellular symbionts until most of their DNA migrated to the nucleus of the host over a billion years ago - a process that profoundly shaped the structure and content of the eukaryote genome and cell (Timmis et al. 2004; Martin 2003). (9) Now, to obtain the proteins they need for many functions, including their own metabolic activities, mitochondria and plastids rely on a protein import mechanism provided by the host's cellular machinery (Thiessen and Martin 2006; Cavalier-Smith and Lee 1985). This loss of genetic autonomy is not total, however, because plastids and mitochondria retain genes for translation and transcription machinery as well as metabolic function. They divide and grow independently of the cell cycle, although mitochondria gain some division assistance from the host cell (Osteryoung and Nunnari 2003). As well as inheriting their membranes directly, both organelles inherit their own organelle-specific DNA. 
Mitochondria and plastids are not only essential to their cellular hosts, but are defining characteristics of them: there are no eukaryotes without mitochondria or plants without plastids. (10) Again, it is obvious that collaboration is happening here in ways that benefit - and make dependent - both organelles and the cells they inhabit. Indeed, the eukaryote cell could no more survive without its mitochondrial residents than the latter could survive in natural circumstances outside the cell.

\subsection{Viruses}

Viruses are typically very small packages of single- or double-stranded DNA or RNA (11) (often just a few genes), wrapped up in a coating of protein and sometimes an additional lipid envelope. (12) They are prolific, highly diverse and ancient, although there is incomplete agreement about their evolutionary origins (as we shall see below). Viruses are generally excluded from organismal status because although they can synthesize some of their own proteins, they do not metabolize or reproduce independently (Van Regenmortel 2007). They either use their hosts, which probably include every organism past and present, or occasionally work in collaboration with other viruses to make necessary enzymes. Viruses do not reproduce by division but by self-assembly of the components that they manufacture with the help of the host cell. Some viruses influence host behaviour quite significantly by, for example, conferring either protection against other viruses or virulence properties (e.g., diphtheria or cholera toxins).

Viruses have well defined life cycles that are often described as consisting of 'developmental' stages (e.g., Luria et al. 1978). The cycle begins with virions, the inert form of viruses, which are transformed into the next stage of adsorption, when viruses or phages (the viruses with affinities for prokaryotes rather than eukaryotes) 'dock' onto the outer cell membrane of their hosts and either enter the cell or have their DNA absorbed into it. Their protein coats dissolve or are discarded, after which the viruses co-opt the host's cellular machinery to express genes that lead to genome replication, maturation (in which the new genomes are wrapped in freshly synthesized protein) and, finally, exit the intact or lysed cell. A number of plant viruses move actively from cell to cell, using virus-encoded movement proteins (Boevink and Oparka 2005). Some viruses have an extra developmental stage in which they remain dormant in the host cell or genome as prophages or proviruses and are inherited (Casjens 2003; Bannert et al. 2004). Endogenous retroviruses, which are viruses that have integrated permanently into the host chromosomes and are inherited vertically, have left their mark on many organismal genomes, including our own (Griffiths 2002; Hamilton 2006). Included amongst these viruses are those that are crucial for the development of the placenta in mammals (Mallet et al. 2004).

The diversity and mutability of viruses makes them difficult to classify, although both genome sequence and protein structure analyses are constantly refining viral groupings, which were once based primarily on pathogenic effect (Bamford et al. 2005). The term 'species' is often applied, with many caveats, to subgroups of virus divisions (Lawrence 2002; Hendrix et al. 1999; Van Regenmortel 2007). The aim of such language is to 'bring the definition of virus species into line with the species definitions of cellular organisms' (Gibbs and Gibbs 2006, 1419). One earlier and another more recent division of life into superkingdoms give viruses a superkingdom (domain) of their own: the Acytota or Akamara, both of which are categories for acellular organisms possessing genomes (Jeffrey 1971; Hurst 2000; Weinbauer 2004). These domain-level classification schemas have the potential to identify viruses as genuine forms of life but have yet to gain many adherents.

There are three main hypotheses about the origins of viruses: primeval pre-cellular life (the virus-first or primordial hypothesis), degenerate intracellular parasites (the reduction or regression hypothesis), and as renegade prokaryote genes (the escape hypothesis). The most popular is currently the third one, which is that viruses are actually genetic elements that opted out of cellular organization and are thus true instantiations of 'selfish' genetic material (Campbell 2001; Hendrix et al. 2000). However, new versions of the primordial hypothesis are also being promoted. They shift the discussion back to the pre-cellular 'unselfish' gene pool and give viruses major roles as evolutionary innovators (e.g., Forterre 2006; Koonin et al. 2006; Hendrix 2002; Hendrix et al. 2000; Claverie et al. 2006). Whatever their origins, viruses have made extraordinary contributions to the evolution of non-viral life through their proclivity for mutation and recombination, and their ability to pick up and move genes from one organism to another (transduction) and integrate their own 
and other genetic material into host genomes (Weinbauer and Rassoulzadegan 2004; Lawrence et al. 2002; Karam 2005; Villarreal 2004; Hambly and Suttle 2005). Moreover, their role as carbon regulators in the global oceans, for example (Suttle 2005), shows how a broader conception of collaboration is necessary to understand the evolutionary, biogeochemical and ecosystemic contributions of viruses to all living systems.

The recently discovered Mimivirus (short for 'mimicking microbe') provides an additional challenge to some prevalent ideas about viruses and their capabilities. Mimiviruses are huge (larger in volume and genome size - over 900 protein-coding genes - than many of the smallest bacteria, some of which are described below) and, most surprisingly, they carry genes that are known to encode translation, DNA repair and metabolic activities (Raoult et al. 2004). (13) They do not seem to have picked these genes up from their hosts. (14) Although these viruses cannot synthesize their own ribosomes and do not metabolize unaided (their metabolic pathways are incompletely coded), they can easily be conceived of as entities in transition from viruses to free-living organisms (Forterre 2006; Raoult 2005; Claverie et al. 2006). Mimiviruses certainly exhibit more independence than organelles and, moreover, seem to be in an 'evolutionary steady state' with no apparent signs of genome reduction (Claverie et al. 2006, 142).

Microbiologists and other biologists are highly ambivalent about the biological status of viruses. Although a strong line of thinking throughout much of the history of virus research and microbiology has advocated that viruses are alive and at least proto-organismal (Burnet 1945; Stanley 1941; 1957; Luria et al. 1978; van Helvoort 1992), the dominant view of viruses is still fixed by the assumption that only cellular entities are appropriately designated as living (Moreira and López-García 2009). According to virologist Marc Van Regenmortel:

Only unicellular and multicellular organisms possess the property of being alive while the organelles, macromolecules and genes found in cells are not themselves considered to be alive. The differences between viruses [which are not alive] and various types of organisms is quite obvious when the functional roles of the proteins found in viruses and organisms are compared $(2007,133)$.

Other microbiologists, however, believe that there are numerous reasons to give viruses the status of living matter. Because they 'have the intrinsic ability to mediate their own transfer from one host to another,' say Salvador Luria and co-authors:

Viruses are independent genetic systems. They are not accidentally separated fragments of a cell genome. They are endowed with genetic continuity and mutability, and contain sets of genes working in concert to make more virus. They have their own evolution, which is independent, to some extent at least, of the evolution of organisms in which they reproduce (Luria et al. 1978, 481).

Some virologists go even further and argue that viruses exhibit the same primary features common to all life forms, such as internal homeostatic controls that enable survival in changing environments, organization that is based on heritable nucleic acids, reproduction, exploitation of environmental resources, diversity of components and their functions, and the capacity to adapt and evolve (Mindell and Villarreal 2003, 1677; Mindell et al. 2003; Stanley 1941; 1957). Discovery of the debilitating effects of a minute 'virophage' on a huge virus has been argued as evidence for the aliveness of viruses: if they can be infected themselves, and respond in various ways to these infections, then the 'imaginary boundary' between viruses and true organisms seems to have been crossed (Claverie, Koonin, in Pearson 2008).

A further stream of reflection sees no contradiction in regarding viruses as alternating between living and non-living phases:

Outside the host cell, poliovirus is as dead as a ping-pong ball. It is a chemical that has been purified $\ldots$ and crystallized ... with its physical and chemical properties largely determined ... and its threedimensional structure solved. Just like a common chemical, poliovirus has been synthesized in the test-tube. Once poliovirus, the chemical, has entered the cell, however, it has a plan for survival. Its proliferation is then subject to evolutionary laws: heredity, genetic variation, selection towards 
fitness, evolution into different species and so forth-that is, poliovirus obeys the same rules that apply to living entities (Wimmer 2006, 56).

The inertness of virions outside the cell leads us to think that viruses are similar to prokaryotes with spore stages as well as to plant seeds and fungal spores. In our conclusion we shall (cautiously) endorse this perspective, and also suggest that it is helpful to distinguish the developmental cycle, which includes both active and inert stages, from the life cycle, which should be applied only to metabolically active phases of lineage-forming systems.

Historical echoes of the discussion of the status of viruses are amplified by recent practical achievements of creating synthetic viral genomes. Several of these have now been synthesized from scratch and used successfully to infect cells (e.g., Tumpey et al. 2005; Smith et al. 2003; Cello et al. 2002). Some of these researchers claim their achievements are the final nails in the coffin of vitalism, because their virus 'chemical' was resurrected in a cellular extract and not a living cell (e.g., Cello et al. 2002). However, those who do not see viruses as organisms perceive synthetic viral genomes as further proof that 'true' (cellular) life - still resistant to synthesis from the top down or bottom up - is something fundamentally different from the much more easily created biology of viruses or plasmids.

It is clear to us that leaving viruses out of evolutionary, ecological, physiological or conceptual studies of living entities, would allow only an incomplete understanding of life at any level (Weinbauer and Rassoulzadegan 2004; Wilhelm and Suttle 1999; Suttle 2005). This deep and extensive interaction is too biologically important, from our perspective, to be considered as purely parasitic. Conceived of collaboratively, cellular life is constantly 'bathing in a virtual sea of viruses', within and without every cell, with evolutionarily significant consequences for the past, present and future of all cellular lifeforms (Bamford 2003, 232). In fact, says virologist Dennis Bamford (2003, 235), it is time to consider dividing life into two realms: the cellular realm and the viral one. He believes that only by dealing more thoroughly with a concept of life fully cognizant of the role of viruses will we be able to achieve an adequate view of life even as it applies to its cellular manifestations.

\subsection{Endosymbionts}

Endosymbionts are entities that live inside the cells of other organisms. Some are mutualists while others are more parasitic. Parasites are generally distinguished from other symbionts by their mode of collaboration with their hosts. While endosymbionts have a mutual give-take relationship with their hosts, obligate endoparasites are generally viewed primarily as receivers of benefits and not givers. Increasingly, however, these are being understood as more fluctuating and complex relationships (Valdivia and Heitman 2007). Numerous bacteria are obligate parasites that have reduced genomes and depleted cellular function. Rickettsia, Chlamydia (15) and microsporidia are well known examples. Microsporidia have lost so many genomic, biochemical and morphological features that they were once thought to be the most primitive eukaryotes (Keeling and Fast 2002). Now, however, they are deemed to be fungi that are highly adapted to their parasitic lifestyles. Rather than relinquishing their genes to the host genome (as have organelles), obligate endoparasites have simply lost the genes that have become redundant due to reliance on host provisions (Timmis et al. 2004; Tamas et al. 2001). These are usually metabolic and mobility genes, although some of these symbionts retain capacities for intra- and intercellular mobility (Gouin et al. 2004).

Despite the ongoing reduction of their genomes, some of these parasites also acquire and exchange DNA via conjugation and transduction (Darby et al. 2007). Obligate bacterial parasites can be vertically as well as horizontally transmitted, and transmission between mammals and other animals often involves vector organisms such as ticks or fleas (Darby et al. 2007). Another form of symbiosis, 'reproductive parasitism' (Wernegreen 2004), is employed by Wolbachia. These are widespread hereditary endosymbionts of insects, crustaceans, spiders and nematodes. The hosts do not depend on their endosymbionts for metabolism or defence, (16) but the bacteria significantly influence host lives and may induce speciation events by reproductively isolating insect lineages (Charlat et al. 2003; Weeks et al. 2002). Wolbachia control the reproduction and development of many of their hosts by biasing sex ratios and reproductive strategy (asexual rather than sexual), as well as feminizing genetic males (Werren 1997; Stouthamer et al. 1999). In 
addition to being inherited vertically via maternal transmission, Wolbachia spread themselves laterally, sometimes to evolutionarily distant insect hosts. Their genes are also transferred laterally (in one case the entire genome!) into insect host genomes (Dunning-Hotopp et al. 2007).

Many mutualist endosymbionts cannot live without their hosts and the hosts are frequently just as dependent on their endosymbionts. They are almost always transmitted vertically from host to host through the maternal line (Wernegreen 2002). Numerous insects are involved in obligate intracellular mutualisms with bacteria, to the extent that separate insect and bacterial lineages are fused into single, highly coordinated metabolic systems (Wu et al. 2006). These endosymbionts frequently live in specialized cells (bacteriocytes) created within the host organism and their primary endosymbioses are quite commonly associated with secondary endosymbioses (Douglas and Raven 2003; Baumann 2003).

One of the most intensively studied mutualist endosymbionts is Buchnera aphidicola, which lives in tight association with its aphid hosts (about a million Buchnera cells per aphid) and produces essential amino acids for them. It is vertically inherited from one generation of aphids to the next and its few regulatory genes appear to control its life cycle in relation to its aphid host (Moran and Degnan 2006). Buchnera have tiny genomes due to gene loss and no uptake of mobile genetic elements. They are about one-seventh the size of E. coli (although Buchnera cells are actually larger and contain many copies of the genome), with which they shared a common ancestor about 200 million years ago (Moran and Degnan 2006). Aphids and Buchnera coevolve and codiversify, meaning the phylogenies of associated lineages map onto each other (Moran 2006). Buchnera are commonly classed as endosymbionts but the depth of their dependence on their hosts means that some biologists see these bacteria as closer in status to organelles (e.g., Andersson 2000; Douglas and Raven 2003).

One key difference that is often said to distinguish endosymbionts from organelles is that endosymbiont genomes encode most of their essential proteins whereas in organelles, many of the genes for organelle function have shifted to the host genome and been replaced by a protein import apparatus (Cavalier-Smith and Lee 1985, 378; Thiessen and Martin, 2006). Not everyone accepts this distinction, however, and other commentators see variable degrees of biochemical and cellular integration between host and endosymbiont/organelle (e.g., Bhattacharya and Archibald 2006; Bodyt et al. 2007). There certainly appear to be numerous endosymbionts making the transition from organism to organelle status (17) and any definition of either will have to be based on a continuum of collaborative strategies rather than clear categories of distinct entities (Bodyt et al. 2007; Rodríguez-Ezpeleta and Phillipe 2005). Concomitant with observations about the occurrence of these evolutionary transitions from free-living organism to endosymbiont to organelle appears to be a shift in the language used by biologists: from autonomous 'invaders' to domesticated 'servants' to 'captives' or 'slaves' that have almost totally lost their bacterial identity (e.g., Dyall et al. 2004; Baumann 2005).

\subsection{Reduced extracellular symbionts}

A plethora of bacteria and other microbes live in intimate extracellular liaison with plants, animals and fungi (sometimes these arrangements are called ectosymbioses or episymbioses). Cyanobacteria, as well as being ancestral to plastids, live in close symbioses with eukaryotes, providing nitrogen fixing and photosynthesizing capabilities through a variety of mechanisms (Douglas and Raven 2003). Some are vertically transmitted and a few free-living cyanobacteria exhibit trends towards genome reduction very similar to those in endosymbionts (Marais et al. 2007). Some ultimately obligate symbiotic arrangements have free-living stages, such as the Rhizobium bacteria that colonize plant roots and fix nitrogen for their partners.

Fascinating as many of these symbiotic arrangements are (e.g., bacteria that provide 'legs' for ciliates; others that oxidize sulphur for tube worms that lose their mouths and guts as juveniles when colonized by these ectosymbionts), we will focus here on 'transitional' organisms that seem to be on the very edge of 'independent' living. One example is Nanoarchaeum equitans, an exceedingly tiny archaeon, which is always described as an organism despite its extremely reduced genome and consequent inability to metabolize, grow and reproduce independently of another archaeon, Ignicoccus hospitalis (Huber et al. 2002). A betterknown example is the genus Mycoplasma, which consists of very small obligate parasites that are notable for 
having no cell walls (almost all bacteria do, as do plants and fungi but not animals or most protists (18)). They are usually regarded as the smallest free-living cell (19) although they are heavily dependent on their hosts for amino acid and co-factor biosynthesis, and fatty acid metabolism, especially sterols for membrane maintenance (Fraser et al. 1995; Rottem and Naot 1998). They have lost large numbers of their genes and are considered to have 'little adaptive capability' (Glass et al. 2006, 425). (20)

Because of this reduced genome and restricted function, Mycoplasma (M. genitalium in particular) have been popular candidates for minimal cell research, in which synthetic biologists attempt to recreate the simplest cellular form of life from synthetic or engineered components. One of the recent breakthroughs in synthetic biology involved 'rebooting' a Mycoplasma cell with a genome from a different Mycoplasma taxon (Lartigue et al. 2007). Although the experiment was successful, doubts were raised about the transferability of the technique to less closely related organisms and to those with cell walls (Pennisi 2007).

In none of this research, however, is it doubted that Mycoplasma is a living organism, so its dependent nature and restricted function are apparently insufficient reasons to consider it in the same light as a virus. One of the characteristics that tends to confer organismal status is genetic autonomy, or the capability of a biological entity to initiate and complete its own reproduction. This status does not obtain for plastids or organelles, however, which are usually perceived as mere parts of the cell in which they are found. The additional biosynthetic and metabolic capabilities of endosymbionts and exosymbionts, no matter how reduced, seem to be essential to the conferral of organismal status. However, given the complete dependence of these processes on contributions from the host cell, the grounds for this sharp distinction between viruses and (other) symbionts is far from clear.

\subsection{Unicellular organisms and single cells}

It might seem a strange turn in our discussion to interrogate unicellular organisms for whether they are alive or not, when nobody has questioned that status. Our point here, however, is to continue to press the question of whether the boundaries of life are clear cut and, in particular, whether cellularity is enough in itself to confer 'aliveness'. Certainly, a single mammalian cell on a petri dish, for example, is not normally considered a living entity in its own right, (21) in part because of the highly technical requirements for keeping this cell and its descendants alive (Bhardwaj et al. 2006). This ambiguous status is, we believe, the same ambiguity that bedevils our understanding of prions, plasmids, organelles and viruses. Single animal or plant cells are only truly alive when they are collaborating with other cells. Whether prokaryote or eukaryote, microorganismal or macroorganismal, cells work together in a great variety of ways, collectively structuring their activities through numerous mechanisms. In the same way that cellular life-forms are only fully functional when collaborating with other cells, so are viruses, plasmids and prions. Is there a hard line worth drawing between different modes of cellular and subcellular collaboration - between collaboration and exploitation? We think not.

Moreover, even when single cells are considered in isolation, each cell is a complex of collaborating parts. In the case of eukaryote cells, those parts - as we saw in the discussion of organelles - may include once free-living cellular entities. A eukaryote cell, in the minds of some biologists, 'can be likened to a society composed of a nucleus and a crowd of subcellular organelles in which all members cooperate for the common good' (Eberhardt 1980, 231). This is a complex collaboration, however, because competitive reproductive relationships may also exist between organelles or plasmids in a cell (for examples of such competition, see Walsh 1992; Eberhardt 1980; Paulsson 2002). Such competition can also occur between cells in clones, as when somatic mutations occur in the meristems of vegetatively reproducing plants (Klebowski 2003; Pineda-Krch and Fagerström 2001). Although the philosophy of biology has directed considerable attention to the problem of conflict in the transition from single cells to multicellularity (e.g., Okasha 2004), it has not extended a similar level of scrutiny to intracellular cooperation and competition. We believe this is worth doing for a better understanding of these collaborative relationships between biological entities at multiple levels. 


\subsection{Multicellular organisms}

Multicellular organisms, particularly plants and animals, and most notably ourselves, are considered to be 'paradigmatic' examples of living entities (Wilson 2000). Again, we think that this is far from clear, and that whatever aliveness consists of for an animal, for example, it is a much less autonomous state than is usually recognized in discussions of life (especially, but not only, philosophical discussions). The evolution of eukaryotes has largely been driven by microorganismal interactions, and a variety of modes of dependence between eukaryotes and prokaryotes endures and diversifies in every existing eukaryotic organism. Vast numbers of eukaryotes cannot reproduce, develop or metabolize without their prokaryote partners. We noted earlier that achieving organismal status is often understood to be the achievement of autonomy. This interpretation can easily mislead our understanding of life and what it is to be alive. Traditionally conceived biological entities are systems elaborated around unique genomes, but to consider them as autonomous individuals is a mistake, we argue: functional wholeness, the basis of any attribution of autonomy, is a characteristic of collaborative interactions, almost always involving diverse entities.

Not only are paradigmatic multicellular organisms more multicellular than is usually supposed (in that a multicellular organism should be understood as including all the entities that interact to achieve shared metabolic and reproductive goals), but even 'simple' prokaryotes could be thought to qualify for multicellular status on this basis. Take, for example, magnetotactic bacteria, which have organelles of magnetic crystals (magnetosomes) that line up inside the cell and are attached to the flagella of the bacteria. The magnetosomes function as compasses and guide the bacteria along local magnetic field lines (preferentially north or south, depending on which hemisphere the bacteria live in). As if this were not astonishing enough, some magnetotactic bacteria live in strictly multicellular arrangements. The individual cells form a spherical group of up to 40 bacteria, constructing an empty compartment in the middle of the group. As well as sensing magnetic lines together and moving in a fully coordinated manner, the groups reproduce together by coordinated cell division. They grow at the same rate (increasing in volume, not cell number) and then simultaneously divide into a new multicellular organism that swims off immediately after separation (Keim et al. 2004; 2007; Abreu et al. 2007). Most multicellular organisms have a unicellular stage, whereas these magnetotactic bacteria have a strong claim to be exclusively multicellular throughout their life cycle. (22)

More variable in their organization than magnetotactic bacteria and other specialized multicellular structures of unicellular organisms (such as the well known aggregating examples of Dictyostelium and myxobacteria) are other collaborative arrangements known as communities. Prokaryotes and other microbes seldom live as isolated single cells but cohabit in a variety of communal organizations such as biofilms. Microorganisms that live as parts of biofilms express genes very differently from free-floating (planktonic) microbes, and in patterns that are structured at each stage of the biofilm's development (Stoodley et al. 2002; Costerton et al. 1995). Communities such as biofilms (which may be single or multi-taxa), as well as some populations of unicellular organisms, exhibit well-defined cell organization and a functional division of labour that includes specialized cell-to-cell interactions, the suppression of cellular autonomy and competition, metabolic collaboration, combined defence and attack strategies, and the coordination of movement, growth and reproduction (Cho et al. 2007; Aguilar et al 2007; Kaiser 2001; Shapiro 1998; Kolenbrander 2000; Crespi 2001; Dworkin 1997). Many of these are activities that no individual microbe can accomplish on its own, and the collective behavior is often achieved with a cost for individual 'altruistic' microorganisms (if they are perceived through the lens of selfishness).

Some biologists and philosophers may prefer to define multicellularity in ways derived from reflection on animals and plants, and thereby exclude these microbial communities from that category. But certainly any general account of the varieties of biological organization will need to take account of them and explain how they conform to concepts such 'multicellularity', 'invididuality' and 'autonomy'. Do humans, for example, stop at their skin and have to be conceived of as tubular rather than solid in order to avoid incorporating large internal populations of gut microbes? Lederberg, with his concept of 'symbiome', raises the question of whether organisms are necessarily monogenomic or whether a multi- or metagenomic state is the usual state of organismal organization (Lederberg, in Hooper and Gordon 2001; Dupré and O'Malley 2007). Discussions of life and its organization have to take into account the fact that symbiotic relationships 
are ubiquitous and all organisms, when conceived as the functional wholes that interact with their surroundings, are multi-lineal and multigenomic.

All multicellular organisms function with the inherited assistance of endosymbiotic partners in interplay with numerous other forms of partnership. All unicellular organisms are infected with phages and other unicellular organisms, and even viruses have their own phages, 'virophages' (La Scola et al. 2008). Although viruses are generally thought of as strictly parasitic, this view may owe more to preconception than to biological fact. The functions of micro-alliances with viruses are only beginning to be investigated, and one early investigative success has been delineating the contribution of cyanophages to cyanobacterial photosynthesis (Lindell et al. 2005). Similarly, the phages that infect the anthrax bacterium, Bacillus anthracis, play major roles in the bacterium's capacity to build communities and to produce the long-lived spores that ensure the perpetuation of the cycle of anthrax infections in animals (Schuch and Fischetti 2009). More broadly, the role of viruses as facilitators of genetic variation in multi-lineage communities and as fundamental agents in biogeochemical cycles (Suttle 2005) means they cannot be assumed to be exclusively parasitic and self-serving.

Overall, deep and extensive collaborations between biological entities blur - at the very least - any distinction between so-called individual organisms and these larger organismal groupings of which they are parts (Moran 2006; Dyer 1989). They also call attention to the non-discrete and highly dynamic nature of biological individuals (Rayner 1997). Although this is not our present focus, we should note that great evolutionary significance has been attributed to symbiosis (e.g., Sapp 1994). Symbioses have constituted innovations that have made possible some of the most significant transitions in evolutionary history, as our discussion of mitochondria and plastids made clear.

\section{Characteristics of living biological entities}

\subsection{Common criteria of life}

How is it usually decided which of these diverse entities is alive? All the definitions of life in current circulation emphasize particular life-bestowing properties. Some of these definitions take functional criteria (such as reproductive autonomy) to be the most important, whereas others emphasize evolutionary criteria, such as continuity or evolvability, or foreground metabolic or organizational characteristics (Popa 2004; Koshland 2002; Pályi et al. 2002; Zhuravlev and Avetisov 2006; Szathmáry 2006). The most inclusive range of criteria for deciding whether entities are alive or not is derived from exemplars already regarded as unquestionably alive. Animal characteristics often dominate these criteria, which are then modified to include plants, fungi and unicellular organisms but to exclude entities such as fire and crystals (Chyba and Hand 2005).

Spatial boundedness is widely assumed to be a fundamental criterion of living entities, and is one reason larger biological systems, such as ecosystems, are seldom classified as living entities in their own rights. Boundaries usually consist of enclosing materials such as membranes, cell walls and skin, which separate internal from external environments and enable internal activities such as metabolism (Popa 2004). Associated with spatial boundedness, and again almost inescapably connected to the project of distinguishing coherent subunits from encompassing systems, are stability and the ability to maintain a buffer against fluctuating environments. However, the interconnectedness of the diverse entities discussed in the preceding text points to obvious dangers in assuming that spatial boundaries can be straightforwardly and uniquely identified (Rayner 1997). The boundaries of a plant and animal are precisely the sites where complex interactions occur between entities generally considered distinct, but these interactions are so closely coupled that we are strongly tempted to see them as parts of the same system. (23)

Perhaps the most widely agreed criteria for being a living thing are metabolism, or energy transformation, and reproduction, the capacity of entities to make more of themselves. Biochemical transformation of energy from the environment, first to maintain their own structural and functional integrity, and second to reproduce themselves, is a plausible general account of what living things most fundamentally do. Metabolism, then, is a basic means of survival for anything alive. (24) For many biologists, this is the most 
fundamental biological process and the true demarcator of living and non-living entities (Gánti 1997; Luisi 1998). An internal capacity for self-sustainability on the basis of the processing of external resources is a common understanding of organismal function (Luisi 1998).

Our reservations about this criterion are not about whether metabolism is a basic characteristic of living systems, but whether it can effectively be deployed to make the kinds of distinctions into discrete living entities that are generally expected by theorists of biology. The reason for this is that metabolism is typically a collaborative activity involving many of the things that are generally supposed to be discrete living entities. It is generally supposed, for example, that a human, qua discrete biological entity, consists of a lineage of cells deriving in a series of divisions from an original zygote. But a functional human consists also of very large numbers of symbiotic bacteria, in fact amounting to $90 \%$ of the cells in the total human system. These microbial cells are deeply involved in the metabolic processes, most obviously digestion, that maintain the functioning of the system (Gill et al. 2006; Hooper and Gordon 2001). Hence, a human, conceived in the way just described, is not capable of performing autonomously the metabolic processes essential for its survival. If it is considered sufficient merely to carry out independently some metabolic processes, but not all those necessary for the survival of the entity, then organelles and endosymbionts will count as living entities.

While we noted earlier that reproduction is a necessary feature of life, we also mentioned its inadequacies for a full understanding of life. As we have shown, viruses, organelles and even prions reproduce themselves. The reproduction criterion is sometimes tied to autonomous reproduction, so that viruses and the like, though they are very effective replicators, are often taken to fail this criterion because they do not reproduce independently and must use 'true' organisms from different lineages to achieve their reproduction. However, it is doubtful whether even paradigmatic multicellular organisms can meet the criterion of lineage-exclusive autonomous reproduction. Those insects in which reproduction is substantially under the control of endosymbiotic Wolbachia are one obvious counterexample. But more generally, insofar as reproduction requires the deployment of metabolic processes, as it surely must, it depends also on endoand exosymbiotic microbes.

Another criterion sometimes proposed as definitive of life is evolvability (Ruiz-Mirazo et al. 2004). One highly cited definition of evolvability is that provided by Marc Kirschner and John Gerhart, in which 'evolvability is an organism's capacity to generate heritable phenotypic variation' (1998, 8420). A consequence of taking this as criterial for living entities is that it would include all the entities we have described down to viruses and prions. Our interest in the concept, however, is rather to make a much more general point which, we think, cuts to the heart of the difficulty in defining a living entity. Evolvability, in the sense of Kirschner and Gerhart at any rate, is a characteristic of lineages. Viruses, prions, organelles, unicellular organisms, and multicellular organisms conceived as monogenomic wholes, all form the appropriate kinds of lineages. So, although we agree that these criteria of spatial boundedness, metabolism, reproduction and evolvability are truly important to understand life, we believe that they are being understood within a framework that misconceives living entities in a fundamentally important way.

\subsection{Reframing the criteria of life}

Our reservations about the above criteria arise from the fact that none of the entities we discuss are the functional entities that interact with their environment and whose success or failure in such interaction determines the success or failure of these lineages. These functional entities are, rather, associations of a variety of such lineage-forming entities. A typical large eukaryote, for instance, is constituted by entities of all the kinds we have distinguished above. We might invoke here David Hull's (1980) well-known distinction between replicators and interactors, but in a very different way from that originally supposed by Hull. Interactors, in our view, are complex systems involving the collaboration of many highly diverse lineageforming entities. This sort of interactor, we also suggest, is the most fundamental unit of selection. This perspective has radical implications for the way we think about evolution. It would entail but obviously go beyond contemporary concepts of group selection in multi-level selectionism (Sober and Wilson 1998).

Amongst those implications is the importance of the notion of collaboration, which is seldom proposed as a criterion of life (although see, e.g., Lezon et al. 2006, for an emphasis on cooperation). It is hard to imagine life that is not collaborative, in the sense described above, both at the intracellular and the 
intercellular level, and we suggest that collaboration is, therefore, one of the central characteristics of life. To treat it as such it will be necessary to specify more carefully what the relevant sense of collaboration entails. We do not want to rule out automatically even simple chemical systems. Some chemical aggregations exhibit growth, reproduction (leading to lineage formation of varying persistence), error correction and environmental sensitivity (Schulman and Winfree 2007; Weber 2007). It would be surprising if these features were not to be found in the chemical world, because otherwise it would be hard to imagine how life would have originated. Our continuum view of life is open to chemical systems being sometimes describable as living systems, though perhaps it is likely that they will meet the relevant criteria only transiently. Because biological entities in our conception are series of dynamic and diverse collaborations, boundaries are flexible and unfixed. Any claim that something is a living thing needs to be assessed in relation to the general characteristics we describe. (25)

But more important than any attempt to specify limits on what is or is not alive will be to emphasize the contrast between this perspective on life as collaborative and the much more familiar assumption that life is fundamentally selfish and entails competition between reproductively and metabolically autonomous organisms. The outlines of our response to the view that only selfish entities will win out in the battle of all against all should by now be clear: The unit of selection, the entity in which selfishness may perhaps be expected as the norm, is a collaboration of many different lineage-forming entities.

The context in which the latter evolve, then, is quite typically one of collaboration. We said that the collaborative whole may perhaps be expected typically to display selfishness. But, of course, this assumes that there is some natural terminus to the process of collaboration. We hypothesize that competitive activity is a transitional rather than a terminal state and that such temporarily competitive wholes will exhibit a strong tendency ultimately to compete most successfully by engaging in new levels of collaboration with similar or different entities. We see the emergence of sociality as an instantiation of such a process as are, more generally, the evolutionary transitions that have been highlighted by the work of John Maynard Smith and Eörs Szathmáry (1995). Our spectrum of biological entities exemplifies a number of different forms of collaboration that are central to such an evolutionary schema. As we have emphasized, our concept of collaboration assumes no sharp boundary between selfish and cooperative interactions, something surely to be expected if the former is inclined to evolve into the latter.

We have certainly not exhausted the criteria that have been proposed as characteristic of living entities. We have not explicitly considered, for example, environmental responsiveness, the ability to detect and respond appropriately to salient features of environments, or development, the recurrent production of the characteristic stages of a life cycle (although much that we have said has addressed these criteria implicitly). We do not mean to minimize the significance of these, and perhaps other, distinctive characteristics of living systems. What we do argue is that a focus on metabolism and reproduction, widely agreed to be fundamental features of life, has the additional virtue of drawing attention to a characteristic that has been greatly underemphasized: that of collaboration. That this has been downplayed is a readily intelligible consequence of the importance that has been attached by biological theorists to competition (Roughgarden 2009). But for this very reason giving collaboration proper emphasis could provide important fresh insight into the nature of evolutionary processes because it affects how we conceptualize the entities and activities central to evolution.

\section{Autonomy and the origins of life}

Our collaborative interpretation of life suggests that it is possible to sidestep the usual problems associated with defining life. Although we do not claim to have provided a definition of life, we do believe we have offered a view of living matter that offers a flexible resource for understanding the many ways in which life can be organized. The tension between replicating lineages as one criterion of life, and metabolic selfsustainability as the other, can be reconciled by taking a much more interactive view of metabolic processes and by reconceiving cooperation and competition within a broader framework of collaboration. Life, according to our analysis, occurs at the intersection of lineage formation and (typically collaborative) involvement in metabolism. Entities that are problem cases, such as viruses, can be understood as alive when 
actively collaborating. When not collaborating, they have at most a potential for life. We invite our readers to apply our framework further along the spectrum than we have gone, to various chemical and physical systems and to ecosystems.

What of the autonomous individual organism, often the conceptual target of attempts to define life, and the thing that is assumed by models of evolution through competition and selection? To the extent that such individual autonomy requires just an individual life or life history, then it surely applies much more broadly than is generally intended by biological theorists. Countless non-cellular entities have individual life-histories, which they achieve through contributing to the lives and life-histories of the larger entities in which they collaborate, and this collaboration constitutes their claim to life. But - and this is our central point - no more and no less could be said of the claims to individual life histories of paradigmatic organisms such as animals or plants; unless, that is, we think of these as the collaborative focus of communities of entities from many different reproductive lineages. In much the same way, whatever sense we might try to make of the Dawkinsian idea of selfish genes, molecular replication is always, and has always been from the pre-cellular molecular community to the present, the achievement of ensembles of molecules, not of individual molecules (Segré and Lancet 2000).

It is entirely reasonable to think of autonomy as centrally exhibited in collaboration rather than just rugged independence. Assuming that this kind of autonomy is what is needed to be a living thing, our account therefore includes viruses as not only living matter, but as full-blown living entities when they enter cells and interact with the cell's metabolic capacities. As virions, they are still lineage elements but are temporarily disengaged from metabolic collaboration (likewise bacteria such as Chlamydia in their inert sporelike state and perhaps even many plant seeds and fungal spores). This is why we suggested above that viruses should strictly be described as having developmental cycles rather than life cycles. (26)

Taking this perspective not only renders unproblematic the idea of an entity being sometimes living and at other times non-living but also reinforces the idea of life and the evolution of life as a continuum of collaborativity. Given the acceptance that life has evolved from a chemical context, ruling out self-replicating complexes of chemicals and molecules on the grounds that they are not cells seems misguided. A commitment to life as exclusively cellular and monogenomically organismal would mean that the origins of life must involve a single leap from fully non-living to fully living, something that is conceptually difficult to accept and, for that matter, provides a natural target for creationists to insist on the need for supernatural intervention. The spectrum of biological entities we have described shows that an inflexible dichotomy of life and non-life is, in any case, highly problematic, even for making sense of the entities that now exist. Our more generous framework can encompass a range of theories about the organization and evolution of precellular life which give prions, plasmids and viruses important roles, as well as other macromolecular complexes (e.g., Rode et al. 1999; Lupi et al. 2006; 2007; Eberhard 1990; Kado 1998; Koch 1995).

We also think that our thesis of multi-modal, interconnected and overlapping life processes suggests a more continuous vision of evolutionary history. Many discussions of early life posit a radical transition from a community of genetic exchange to one of restricted vertical inheritance, cellular autonomy and stable genealogy (Woese 2005; Dawkins 2008). Although some biologists believe that pre-cellular life is best conceived as 'unselfish' communality in which genetic resources are shared (Woese et al. 2000), others such as Dawkins presume that pre-cellular life was driven by selfish replication, and that promiscuous horizontal exchange simply extends the opportunities for selfishness (Dawkins 2008). Rather than restricting some evolutionary processes to a discontinued past, we prefer to incorporate them into a schema that allows for the continuity of lateral gene transfer as an important characteristic of today's collaborative evolution.

We find here the reflections of Norris et al. (2007) and Hunding et al. (2006) very helpful. They argue that life evolved as a 'diverse interacting community of molecules' - a 'pre-biotic ecology' that implies a more ecological and community-based view of any biological entity, pre- or post the evolution of cells. Their model describes

the emergence of life as a functional ecological system through a process of integration from diverse components, not as a single entity ... there is no identifiable point at which life emerged. Rather, [it is] a continuous process by which increasingly complex, integrated, self-replicating, autocatalytic, 
module systems evolve new properties in tandem with their environments (Hunding et al. 2006, 409-410).

We believe this sort of dynamic system-based scenario fits more appropriately what we know of the rest of the evolution of life. (27) Evolutionary history suggests that life involves a range of coevolving hierarchies, and that non-life and life share a huge and biologically significant territory that buffers and makes more complex any account of either. Ecology presents us with scenarios of collaboration at least as compelling as those that highlight competition, and the former are rapidly increasing our understanding of the macrobial and microbial world (Dupré and O'Malley 2007). Thinking of life as the result of the intersection of lineage-forming, metabolically collaborative matter, organized within different interacting levels, allows a smooth transition from the earliest living matter to standard examples of life and beyond them all the way up to contemporary ecosystems. A general account such as ours is not, and need not be, definitional. It is, however, sufficient to encompass what is known about an ever more striking variety of biological entities and their evolutionary histories, and to reorient approaches to life around a biologically realistic interpretation of collaborativity.

\section{Literature Cited}

Abreu, F, JL Martins, TS Silerira, CN Keim, HGPL de Barros, FJG. Filho and U Lins. 2007. 'Candidatus Magnetoglobus multicellularis', a multicellular, magnetotactic prokaryote from a hypersaline environment. International Journal of Systematic and Evolutionary Microbiology 57: 1318-1322.

Aguilar, C, H Vlamakis, R Losick and R Kolter. 2007. Thinking about Bacillus subtilis as a multicellular organism. Current Opinion in Microbiology 10: 638-643.

Ahlquist, P. 2006. Parallels among positive-strand RNA viruses, reverse-transcribing viruses and doublestranded RNA viruses. Nature Reviews Microbiology 4: 371-382.

Andersson, JO. 2000. Evolutionary genomics: Is Buchnera a bacterium or an organelle? Current Biology 10: R866-R868.

Archibald, JM. 2007. Nucleomorph genomes: Structure, function origin and evolution. BioEssays 29: 392-402.

Bamford, DH. 2003. Do viruses form lineages across different domains of life? Research in Microbiology 154: 231-236.

Bamford, DH., JM Grimes and DI Stuart. 2005. What does structure tell us about virus evolution? Current Opinion in Structural Biology, 15, 655-663.

Bannert, N and R Kurth. 2004. Retroelements and the human genome: New perspectives on an old relation. Proceedings of the National Academy of Sciences USA 101 (Suppl. 2): 14572-14579.

Barton, BM, GP Harding and AJ Zuccarelli. 1995. A general method for detecting and sizing large plasmids. Analytical Biochemistry 226: 235-240.

Baumann, P. 2005. Biology of bacteriocyte-associated endosymbionts of plant sap-sucking insects. Annual Review of Microbiology 59: 155-189.

Bhardwaj, U, Y-H Zhang, Z Rangwala and ERB McCabe. 2006. Completely self-contained cell culture system: from storage to use. Molecular Genetics and Metabolism 89: 168-173.

Bhattacharya, D and JM Archibald. 2006. The difference between organelles and endosymbionts - response to Theissen and Martin. Current Biology 16: R1017-R1018.

Bingle, LEH and CM Thomas. 2001. Regulatory circuits for plasmid survival. Current Opinion in Microbiology 4: 194-200.

Bodyt, A, P Mackiewicz and JW Stiller. 2007. The intracellular cyanobacteria of Paulinella chromatophora: Endosymbionts or organelles? Trends in Microbiology 15: 295-296.

Boevink, P and KJ Oparka. 2005. Virus-host interactions during movement processes. Plant Physiology 138: 1815-1821.

Bousset, L and R Melki. 2002. Similar and divergent features in mammalian and yeast prions. Microbes and Infection 4: 461-469. 
Braun SSv and E Schleiff. 2007. Movement of endosymbiotic organelles. Current Protein and Peptide Science 8: 426-438.

Burnet, FM. 1945. Virus as Organism: Evolutionary and Ecological Aspects of Some Human Virus Diseases. Harvard University Press.

Campbell, A. 2001. The origins and evolution of viruses. Trends in Microbiology 9: 61.

Casjens, S. 2003. Prophages and bacterial genomics: What have we learned so far? Molecular Microbiology 49: 277-300.

Cavalier-Smith, T. (2000). Membrane heredity and early chloroplast evolution. Trends in Plant Science 5: 174-182.

Cavalier-Smith, T and JJ Lee. 1985. Protozoa as hosts for endosymbioses and the conversion of symbionts into organelles. Journal of Protozoology 32: 376-379.

Cello, J, AV Paul. and E Wimmer. 2002. Chemical synthesis of poliovirus cDNA: Generation of infectious virus in the absence of natural template. Science 297: 1016-1018

Charlat, S, GDD Hurst and H Merçot. 2003. Evolutionary consequences of Wolbachia infections. Trends in Genetics 19: 217-223.

Chernoff, YO. 2001. Mutation processes at the protein level: Is Lamarck back? Mutation Research 488: $39-64$.

Chernoff, YO, AP Galkin, E Lewitin, TA Chernova, GP Newnam and SM Belenkly. 2000. Evolutionary conservation of prion-forming abilities of the yeast Sup35 protein. Molecular Microbiology 35: 865-876.

Cho, J, H Jönsson, K Campbell, P Melke, JW Williams, B Jedynak, AM Stevens, A Groisman and A Levchenko. 2007. Self-organization in high-density bacterial colonies: Efficient crowd control. PLoS Biology 5(11): e302.

Chyba, GF and KP Hand. 2005. Astrobiology: The study of the living universe. Annual Review of Astronomy and Astrophysics 43: 31-74.

Claverie, JM, H Ogata, S Audic, C Abergel, K Shure and PE Fournier. 2006. Mimivirus and the emerging concept of 'giant' virus. Virus Research 117: 133-144.

Collings, DA, JDI Harper, J Marc, RL Overall and RT Mullen. 2002. Life in the fast lane: Actin-based motility of plant peroxisomes. Canadian Journal of Botany 80: 430-441.

Costerton, JW, Z Lewandowski, DE Caldwell, DR Korber and HM Lappin-Scott. 1995. Microbial biofilms. Annual Review of Microbiology 49: 711-745.

Crespi, BJ. 2001. The evolution of social behaviour in microorganisms. Trends in Ecology and Evolution 16: 178-183.

Gutler, S and D Ehrhardt. 2000. Dead cells don't dance: Insights from live-cell imaging in plants. Current Opinion in Plant Biology 3: 532-537.

Darby, AC, NH Cho, HH Fuxelius, J Westberg and SGE Andersson. 2007. Intracellular pathogens go extreme. Trends in Genetics 23: 511-520.

Dawkins, R. 1976. The Selfish Gene. Oxford University Press.

Dawkins, R. (2008). Life: A gene-centric view: Craig Venter and Richard Dawkins. A conversation in Munich. (Transcript). Edge, 235, Feb 6. Retrieved February 24, 2008, from www.edge.org/documents/ archive/edge235.html\#life (also www.edge.org/documents/life/life_index.html)

Derkatch, IL, ME Bradley, JY Hong and SW Liebman. 2001. Prions affect the appearance of other prions: The story of [PIN+]. Gell 108: 171-182.

Doolittle, WF and C Sapienza. 1980. Selfish genes, the phenotype paradigm and genome evolution. Nature 284: 601-603.

Douglas, AE and JA Raven. 2003. Genomes at the interface between bacteria and organelles. Philosophical Transactions of the Royal Society London B 358: 5-18.

Dunning-Hotopp, JCD, ME Clark, DCSG Oliveira, JM Foster, P Fischer et al. 2007. Widespread lateral gene transfer from intracellular bacteria to multicellular eukaryotes. Science 317: 1753-1756.

Dupré, J and MA O'Malley. 2007. Metagenomics and biological ontology. Studies in History and Philosophy of Biological and Biomedical Sciences 38: 834-846. 
Dworkin, M. 1997. Multiculturism versus the single microbe. In Bacteria as Multicellular Organisms. Ed. by JA Shapiro and M. Dworkin (pp. 3-13). Oxford University Press.

Dyall, SD, MT Brown and P Johnson. 2004. Ancient invasions: From endosymbionts to organelles. Science 304: 253-257.

Dyer, BD. 1989. Symbiosis and organismal boundaries. American Zoologist 29: 1085-1095.

Eberhard, WG. 1980. Evolutionary consequences of intracellular organelle competition. Quarterly Review of Biology 55: 231-249.

Eberhard, WG. 1990. Evolution in bacterial plasmids and levels of selection. Quarterly Review of Biology 65: 3-22.

Embley, TM and W Martin. 2006. Eukaryotic evolution, changes and challenges. Nature 440: 623-630.

Fenn, K and M Blaxter. 2006. Wolbachia genomes: Revealing the biology of parasitism and mutualism. Trends in Parasitology 22: 60-65.

Forterre, P. 2006. The origin of viruses and their possible roles in major evolutionary transitions. Virus Research 117: 5-16.

Fraser, CM, JD Gocayne, O White, MD Adams, RA Clayton et al. 1995. The minimal gene complement of Mycoplasma genitalium. Science 270: 397-403.

Galperin, MY. 2005. Life is not defined just in base pairs. Environmental Microbiology 7: 149-152.

Gánti, T. 1997. Biogenesis itself. Journal of Theoretical Biology 187: 583-593.

Gerdes, K, PB Rasmussen and S Molin. 1986. Unique type of plasmid maintenance function: Postsegregational killing of plasmid-free cells. Proceedings of the National Academy of Sciences USA 83: 3116-3120.

Ghigo, JM. 2001. Natural conjugative plasmids induce bacterial biofilm development. Nature 412: 442-445.

Gibbs, AJ and MJ Gibbs. 2006. A broader definition of 'the virus species'. Archives of Virology 151: 1419-1422.

Gill, SR, M Pop, RT DeBoy, PB Eckburg, PJ Turnbaugh, BS Samuel, JI Gordon, DA Relman, CM FraserLiggett and KE Nelson. 2006. Metagenomic analysis of the human distal gut microbiome. Science 312: $1355-1359$.

Glass, JI, N Assad-Garcia, N Alperovich, S Yooseph, MR Lewis, M Maruf, CA Hutchison III, HO Smith and JC Venter. 2006. Essential genes of a minimal bacterium. Proceedings of the National Academy of Sciences USA 103: 425-430.

Gouin, E, C Egile, P Dehoux, V Villiers, J Adams, F Gertier, R Li and P Cossart. 2004. The RickA protein of Rickettsia conorii activates the Arp2/3 complex. Nature 427: 457-461.

Griffiths, DJ. (2001). Endogenous retroviruses in the human genome sequence. Genome Biology 2(6): reviews 1017.1-1017.5.

Grote, M. 2008. Hybridizing bacteria, crossing methods, cross-checking arguments: The transition from episomes to plasmids (1961-1969). History and Philosophy of the Life Sciences 30: 407-430.

Hambly, E and CA Suttle. 2005. The viriosphere, diversity and genetic exchange within phage communities. Current Opinion in Microbiology 8: 444-450.

Hamilton, G. 2006. The gene weavers. Nature 441: 683-685.

Helvoort, Tv. 1992. Bacteriological and physiological research styles in the early controversy on the nature of the bacteriophage phenomenon. Medical History 36: 243-270.

Hendrix, RW. 2002. Bacteriophages: Evolution of the majority. Theoretical Population Biology 61: 471-480.

Hendrix, RW, JG Lawrence, GF Hatfull and S Casjens. 2000. The origins and ongoing evolution of viruses. Trends in Microbiology 8: 504-508.

Hendrix, RW, MCM Smith, RN Burns, ME Ford and GF Hatfull. 1999. Evolutionary relationships among diverse bacteriophages and prophages: All the world's a phage. Proceedings of the National Academy of Sciences USA 96: 2192-2197.

Hood, L and Galas, D. 2003. The digital code of DNA. Nature 421: 444-448.

Hooper, LV and JI Gordon. 2001. Commensal host-bacterial relationships in the gut. Science 292: $1115-1118$.

Huber, H, MJ Hohn, R Rachel, T Fuchs, VC Wimmer and KO Stetter. 2002. A new phylum of Archaea represented by a nanosized hyperthermophilic symbiont. Nature 417: 63-67. 
Hull, DL. 1980. Individuality and selection. Annual Review of Ecology and Systematics 11: 311-332.

Hull, DL. 1988. Science as a Process. University of Chicago Press.

Hunding, A, F Kepes, D Lancet, A Minsky, V Norris, D Raine, K Sriram and R Root-Bernstein. 2006. Compositional complementarity and prebiotic ecology in the origin of life. BioEssays 28: 399-412.

Hurst, C. 2000. An introduction to viral taxonomy and the proposal of Akamara, a potential domain for the genomic acellular agents. In Viral Ecology. Ed by C. Hurst (pp. 41-62). Academic/Elsevier.

Iturbe-Ormaetxe, I. and SL O'Neill. 2007. Wolbachia-host interactions: Connecting phenotype to genotype. Current Opinion in Microbiology 10: 221-224.

Jablonka, E. and MJ Lamb. 2005. Evolution in Four Dimensions. MIT Press.

Jeffrey, C. 1971. Thallophytes and kingdoms - a critique. Kew Bulletin 25(2): 291-299.

Kado, CI. 1998. Origin and evolution of plasmids. Antonie van Leeuwenhoek 73: 117-126.

Kaiser, D. 2001. Building a multicellular organism. Annual Review of Genetics 35: 103-123.

Karam, JD. 2005. Bacteriophages: The viruses for all seasons of molecular biology. Virology Journal 2: 19.

Keeling, PJ. and NM Fast. 2002. Microsporidia: Biology and evolution of highly reduced intracellular parasites. Annual Review of Microbiology 56: 93-116.

Keim, CN., M Farina and U Lins. 2007. Magnetoglobus, magnetic aggregates in anaerobic environments. ASM News 2: 437-445.

Keim, CN, JL Martins, F Abreu, AS Rosado, HL de Barros, R Borojevic, U Lins and M Farina. 2004. Multicellular life cycle of magnetotactic prokaryotes. FEMS Microbiology Letters 240: 203-208.

Kerfeld, CA, MR Sawaya, S Tanaka, CV Nguyen, M Phillips, M Beeby and TO Yeates. 2005. Protein structures forming the shell of primitive bacterial organelles. Science 309: 936-938.

Kirschner, M and J Gerhart. 1998. Evolvability. Proceedings of the National Academy of Sciences USA 95: 8420-8427.

Klekowski, EJ. 2003. Plant clonality, mutation, diplontic selection and mutational meltdown. Biological Journal of the Linnean Society 79: 61-67.

Koch, AL. 1995. The origin of intracellular and intercellular pathogens. Quarterly Review of Biology 70: 423-437.

Kolenbrander, PE. 2000. Oral microbial communities: Biofilms, interactions, and genetic systems. Annual Review of Microbiology 54: 413-437

Komeili, A, Z Li, DK Newman and GJ Jensen. 2006. Magnetosomes are cell membrane invaginations organized by actin-like protein mamK. Science 311: 242-245.

Koonin, EV. 2005. Virology: Gulliver among the Lilliputians. Current Biology 15: R167-R169.

Koonin, EV, TG Senkevich and VV Dolja,. 2006. The ancient Virus World and evolution of cells. Biology Direct 1: 29 doi: 10.1186/1745-6150.1-29.

Kornberg, A. 1989. For the Love of Enzymes: The Odyssey of a Biochemist. Harvard University Press.

Koshland DE Jr. 2002. The seven pillars of life. Science 295: 2215-2216.

Lartigue, C., JI Glass, N Alperovich, R Pieper, PP Parmar, CA Hutchison III, HO Smith and JC Venter. 2007. Genome transplantation in bacteria: Changing one species to another. Science 317: 632-638.

La Scola, B, C Desnues, I Pagnier, C Robert, L Barrassi, G Fournous, M Merchat, M Suzan-Monti, P Forterre, EV Koonin and D Raoult. 2008. The virophage as a unique parasite of the giant mimivirus. Nature 455: 100-104.

Lawrence, JG, GF Hatfull and RW Hendrix. 2002. Imbroglios of viral taxonomy: Genetic exchange and failings of phenetic approaches. Journal of Bacteriology 184: 4891-4905.

Lederberg, J. 1952. Cell genetics and hereditary symbiosis. Physiological Reviews 32: 403-430.

Lederberg, J. 1998. Personal perspective: Plasmid (1952-1997). Plasmid 39: 1-9.

Lezon, TR, JR Banavar and A Maritan. 2006. The origami of life. Journal of Physics and Condensed Matter 18: 847-888.

Liebman, SW and IL Derkatch. 1999. The yeast [PSI+] prion: making sense of nonsense. Journal of Biological Chemistry 274: 1181-1184.

Lindell, D, JD Jaffe, ZI Johnson, GM Church and SW Chisholm. 2005. Photosynthesis genes in marine viruses yield proteins during host infection. Nature 438: 86-89. 
Lowe, M and FA Barr. 2007. Inheritance and biogenesis of organelles in the secretory pathway. Nature Reviews Molecular Cell Biology 8: 429-439.

Luisi, PL. 1998. About various definitions of life. Origins of Life and Evolution of the Biosphere 28: 613-622.

Lupi, O, P Dadalti, E Cruz and PR Sanberg. 2006. Are prions related to the emergence of early life? Medical Hypotheses 67: 1027-1033.

Lupi, O, P Dadalti and C Goodheart. 2007. Did the first virus self-assemble from self-replicating proteins prion proteins and RNA? Medical Hypotheses 69: 724-730.

Luria, SE, JE Darnell, D Baltimore and A Campbell. 1978. General Virology, 3rd ed. Wiley.

Mallet, F, O Bouton, S Proudhomme, V Chaynet, G Oriol, B Bonnaud, G Lucotte, L Duret and B Mandrand. 2004. The endogenonous retroviral locus ERVWE1 is a bona fide gene involved in hominoid placental physiology. Proceedings of the National Academy of Sciences USA 101: 1731-1736.

Manuelidis, L. 2004. A virus behind the mask of prions? Folia Neuropathology Supplement B: 10-23.

Marais, GAB, A Calteau and O Tenaillon. 2007. Mutation rate and genome reduction in endosymbiotic and free-living bacteria. Genetica, doi: 10.1007/s1079-007-9226-6.

Martin, W. 2003. Gene transfer from organelles to the nucleus: Frequent and in big chunks. Proceedings of the National Academy of Sciences USA 100: 8612-8614.

Masel, J and A Bergman. 2003. The evolution of the evolvability of the yeast prion [PSI+]. Evolution 57: 1498-1512.

Maynard Smith, J and E Szathmáry. 1995. The major transitions of evolution. W. H. Freeman.

Meseguer, MA, A Álvarez, MT Rejas, C Sánchez, JC Pérez-Díaz and F Baquero. 2003. Mycoplasma pneumoniae: A reduced-genome intracellular bacterial pathogen. Infection, Genetics and Evolution 3: 47-55.

Mindell, DP, JS Rest and LP Villarreal. 2003. Viruses and the tree of life. In Assembling the Tree of Life. Ed. by J. Cracraft, and M. Donoghue (pp. 107-118). Oxford University Press.

Mindell, DP and LP Villarreal. 2003. Don't forget about viruses. Science 302: 1677.

Moran, NA. 2006. Symbiosis. Current Biology 16: R866-R871.

Moran, NA and PH Degnan. 2006. Functional genomics of Buchnera and the ecology of aphid hosts. Molecular Ecology 15: 1251-1261.

Moreira, D and P López-Gárcia. 2005. Comment on 'The 1.2-megabase genome sequence of Mimivirus'. Science 308: 1114a.

Moreira, D and P López-Gárcia. 2009. Ten reasons to exclude viruses from the tree of life. Nature Reviews Microbiology 7: 306-311.

Muller, HJ. 1966. The gene material as the initiator and the organizing basis of life. American Naturalist 100: 493-517.

Munro, S. 2004. Organelle identity and the organization of membrane traffic. Nature Cell Biology 6: 469-472.

Niftrik, LAV, JA Fuerst, JSS Damsté, JG Kuenen, MSM Jetten and M Strous. 2004. The ammoxosome: An introcytoplasmic compartment in anammox bacteria. FEMS Microbiology Letters 233: 7-13.

Norris, V, A Hunding, F Kepes, D Lancet, A Minsky, D Raine, R Root-Bernstein and K Sriram. 2007. Question 7: The first units of life were not cells. Origins of Life and Evolution of the Biosphere 37: 429-432.

Nunnari, J and P Walter. 1996. Regulation of organelle biogenesis. Cell 84: 389-394.

Okasha, S. 2004. Multi-level selection and the major transitions in evolution. Proceedings PSA 19th Biennial Meeting - PSA 2004: PSA Contributed Papers. PSA.

O’Malley, MA and J Dupré. 2007. Size doesn't matter: Towards a more inclusive philosophy of biology. Biology and Philosophy 22: 155-191.

Orgel, LE. and FHC Crick. 1980. Selfish DNA: The ultimate parasite. Nature 284: 604-607.

Osteryoung, KW and J Nunnari. 2003. The division of endosymbiotic organelles. Science 302: 1698-1704.

Pál, C. 2001. Yeast prions and evolvability. Trends in Genetics 17: 167-169.

Pályi, G, C Zucchi and L Caglioti (Eds.). 2002. Fundamentals of Life. Elsevier. 
Parkin, ET, NT Watt, I Hussain, EA Eckman, CB Eckman, JC Manson, HN Baybutt, AJ Turner and NM Hooper. 2007. Gellular prion protein regulates $\beta$-secretase cleavage of the Alzheimer's amyloid precursor protein. Proceedings of the National Academy of Sciences USA 104: 11062-11067.

Paulsson, J. 2002. Multileveled selection on plasmid replication. Genetics 161: 1373-1384.

Pearson, H. 2008. 'Virophage' suggests viruses are alive. Nature 454: 677.

Pennisi, E. 2007. Replacement genome gives microbe new identity. Science 316: 1827.

Pérez-Brocal, V, R Gil, S Ramos, A Lamelas, M Postigo, JM Michelena, FJ Silva, A Moya and A Latorre. 2006. A small microbial genome: The end of a long symbiotic relationship? Science 314: 312-313.

Perlin, MH 2002. The subcellular entities a.k.a. plasmids. In Modern Microbial Genetics (2nd ed.), Ed. by U. N. Streips, and R. E. Yasbin (pp. 507-560). Wiley.

Pineda-Krch, M, and T Fagerström. 1999. On the potential for evolutionary change in meristematic cell lineages through interorganismal selection. Journal of Evolutionary Biology 12: 681-688.

Popa, R. 2004. Between Necessity and Probability: Search for the Definition and Origin of Life. SpringerVerlag.

Prusiner, SB. 1998. Prions. Proceedings of the National Academy of Science USA 95: 13363-13383.

Puck, TT. 1972. The Mammalian cell as a Microorganism: Genetic and Biochemical Studies in Vitro. Holden-Day.

Raoult, D. 2005. The journey for Rickettsia to Mimivirus. ASM News 71: 278-284.

Raoult, D, S Audic, C Robert, G Abergel, P Renesto, H Ogata, B La Scola, M Suzan and J.-M Claverie. 2004. The 1.2-megabase genome sequence of Mimivirus. Science 306: 1344-1350.

Rayner, ADM. 1997. Degrees of Freedom: Living in Dynamic Boundaries. Imperial College Press.

Rode, BM, W Flader, C Sotriffer and A Righi. 1999. Are prions a relic of an early stage of peptide evolution? Peptides 20: 1513-1516.

Rodríguez-Ezpeleta, N and H Phillipe. 2006. Plastid origin: Replaying the tape. Current Biology 16: R53R56.

Rottem, S and Y Naot. 1998. Subversion and exploitation of host cells by mycoplasmas. Trends in Microbiology 6: 436-440.

Roughgarden, J. 2009. The Genial Gene: Deconstructing Darwinian Selfishness. University of California Press.

Ruiz-Mirazo, K, J Peretó and A Moreno. 2004. A universal definition of life: Autonomy and open-ended evolution. Origins of Life and Evolution of the Biosphere 34: 323-346.

Sapp, J. 1994. Evolution by Association: A History of Symbiosis. Oxford University Press.

Schuch, R. and VA Fischetti. 2009. The secret life of the anthrax agent Bacillus anthracis: Bacteriophagemediated ecological adaptations. PLOS One 4(8): e6532. doi:10.1371/journal.pone.0006532

Schulman, R and E Winfree. 2007. How crystals that sense and respond to their environments could evolve. Natural Computing doi: 10.1007/s1 1047-007-9046-8.

Segré, D and D Lancet. 2000. Composing life. EMBO Reports 1: 217-222.

Seufferheld, M, MCF Viera, FA Fuiz, CO Rodrigues, SNJ Moreno and R Docampo. 2003. Identification of organelles in bacteria similar to acidocalcisomes of unicellular eukaryotes. Journal of Biological Chemistry 278: 29971-29978.

Shapiro, JA. 1998. Thinking about bacterial populations as multicellular organisms. Annual Review of Microbiology 52: 81-104.

Shorter, J. and Lindquist, S. (2005). Prions as adaptive conduits of memory and inheritance. Nature Reviews Genetics, 6, 435-450.

Smith, HO, GA Hutchison III, G Pfannkoch and JC Venter. 2003. Generating a synthetic genome by whole genome assembly: $\Phi$ X174 bacteriophage from synthetic nucleotides. Proceedings of the National Academy of Sciences USA 100: 15440-15445.

Sober E and DS Wilson. 1998. Unto Others: The Evolution and Psychology of Unselfish Behavior. Harvard University Press.

del Solar, G and M Espinosa. 2000. Plasmid copy number control: An ever-growing story. Molecular Microbiology 37: 492-500. 
del Solar, G, R Giraldo, MJ Ruiz-Echevarría, M Espinosa and R Díaz-Orejas. 1998. Replication and control of circular bacterial plasmids. Microbiology and Molecular Biology Reviews 62: 434-464.

Sørensen, SJ, M Bailey, LH Hansen, N Kroer and S Wuertz. 2005. Studying plasmid horizontal transfer in situ: A critical review. Nature Reviews Microbiology 3: 700-710.

Soto, G and GP Saborio. 2001. Prions: Disease propagation and disease therapy by conformational transmission. Trends in Molecular Medicine 7: 109-114.

Stanley, WM. 1941. Some chemical, medical and philosophical aspects of viruses. Science 93: 145-151.

Stanley, WM. 1957. On the nature of viruses, cancer, genes, and life - a declaration of dependence. Proceedings of the American Philosophical Society 101: 317-324.

Stoodley, P, K Sauer, DG Davies and JW Costerton. 2002. Biofilms as complex differentiated communities. Annual Review of Microbiology 56: 187-209.

Stouthamer, R, JAJ Breeuwer and GDD Hurst. 1999. Wolbachia pipientis: Microbial manipulator of arthropod reproduction. Annual Review of Microbiology 53: 71-102.

Suttle, CA. 2005. Viruses in the sea. Nature 437: 356-361.

Szathmáry, E. 2006. The origin of replicators and reproducers. Philosophical Transactions of the Royal Society B 361: 1761-1776.

Tamas, I, LM Klasson, JP Sandström and SGE Andersson. 2001. Mutualists and parasites: How to paint yourself into a (metabolic) corner. FEBS Letters 498: 135-139.

Thiessen, U and W Martin. 2006. The difference between organelles and endosymbionts. Current Biology 16: R1016-R1018.

Thomas, CM. 2000. Paradigms of plasmid organization. Molecular Microbiology 37: 485-491.

Thomas, CM. 2006. Transcription regulatory circuits in bacterial plasmids. Biochemical Society Transactions 34: 1072-1074.

Timmis, JN, MA Ayliffe, CY Huang and W Martin. 2004. Endosymbiotic gene transfer: Organelle genomes forge eukaryotic chromosomes. Nature Reviews Genetics 5: 123-135.

True, HL and SL Lindquist. 2000. A yeast prion provides a mechanism for genetic variation and phenotypic diversity. Nature 407: 477-483.

Tumpey, TM, CF Basler, PV Aguilar, H Zeng, A Solórzano, et al. 2005. Characterization of the reconstructed 1918 Spanish influenza pandemic virus. Science 310: 77-80.

Uptain, SM and S Lindquist. 2002. Prions as protein-based genetic elements. Annual Review of Microbiology 56: 703-741.

Valdivia, RH and J Heitman. 2007. Endosymbiosis: The evil within. Current Biology 17: R408-R410.

Van Regenmortel, MHV. 2007. Virus species and virus identification: Past and current controversies. Infection, Genetics and Evolution 7: 133-144.

Villarreal, LP. 2004. Can viruses make us human? Proceedings of the American Philosophical Society 148: 296-323.

Walsh, JB. 1992. Intracellular selection, conversion bias, and the expected substitution rates of organelle genes. Genetics 130: 939-946.

Warren, G and W Wickner. 1996. Organelle inheritance. Cell 84: 395-400.

Weber, BH. 2007. Emergence of life. Zygon 42: 837-856.

Weeks, AR, KT Reynolds and AA Hoffman. 2002. Wolbachia dynamics and host effects: What has (and has not) been demonstrated? Trends in Ecology and Evolution 17: 257-262.

Wegrzyn, G. 2005. What does "plasmid biology" currently mean? Summary of the Plasmid Biology 2004 Meeting. Plasmid 53: 14-22.

Weinbauer, MG. 2004. Ecology of prokaryotic viruses. FEMS Microbiology Reviews 28: 127-181.

Weinbauer, MG and F Rassoulzadegan. 2004. Are viruses driving microbial diversification and diversity? Environmental Microbiology 6: 1-11.

Weissmann, C. 2004. The state of the prion. Nature Reviews Microbiology 2: 861-871.

Weissmann, G, M Enari, P.-C Klöhn, D Rossi and E Flechsig. 2002. Transmission of prions. Journal of Infectious Diseases 186 (Suppl. 2): S157-S165.

Wernegreen, JJ. 2002. Genome evolution in bacterial endosymbionts of insects. Nature Reviews Genetics 3: 850-861. 
Wernegreen, JJ. (2004). Endosymbiosis: Lessons in conflict resolution. PLoS Biology, 2(3): 0307.

Werren, JH. 1997. Biology of Wolbachia. Annual Review of Entomology 42: 587-609.

Wickner, RB, HK Edskes, ED Ross, MM Pierce, U Baxa, A Brachmann and F Shewmaker. 2004. Prion genetics: New rules for a new kind of gene. Annual Review of Genetics 38: 681-707.

Wickner, RB, HK Edskes, F Shewmaker and T Nakayashiki. 2007. Prions of fungi: Inherited structures and biological roles. Nature Reviews Microbiology 5: 611-618.

Wilhelm, SW and CA Suttle. 1999. Viruses and nutrient cycles in the sea. BioScience 49: 781-788.

Wilson, JA. 2000. Ontological butchery: Organism concepts and biological generalizations. Philosophy of Science 67 (Proceedings): S301-S311.

Wimmer, E. 2006. The test-tube synthesis of a chemical called poliovirus. EMBO reports 7 (Special Issue): S3-S9.

Woese, CR, GJ Olsen, M Ibba and D Söll. 2000. Aminoacyl-tRNA synthetases, the genetic code, and the evolutionary process. Microbiology and Molecular Biology Reviews 64: 202-236.

Woese, CR. 2005. Evolving biological organization. In Microbial Phylogeny and Evolution: Concepts and Controversies. Ed. by J. Sapp (pp.99-117). Oxford University Press.

Wu, D, SC Daugherty, SE Van Aken, GH Pai, KL Watkins, et al. 2006. Metabolic complementarity and genomics of the dual bacterial symbiosis of sharpshooters. PLoS Biology 4(6): e188.

Zhuravlev, YN. and VA Avetisov. 2006. The definition of life in the context of its origins. Biogeosciences 3: 281-291.

\section{NOTES}

(1) Lederberg also includes in his 1998 list heterokaryon cells that have a diversity of nuclei in a common cytoplasm (see Rayner 1997 for details). We will leave these interesting entities out of our discussion.

(2) $\mathrm{PrP}^{\mathrm{C}}$ is the generic protein, and $\mathrm{PrP}^{\mathrm{Sc}}$ is the pathogenic protein isoform. The designation of prion is made in relation to the pathogenic form's still hypothesized function (Weissmann 2004, 863). See Manuelidis (2004) for an argument against the protein-only understanding of prions, in favor of their viral status.

(3) Induction can occur spontaneously, through vertical inheritance or by lateral infection.

(4) The gene encoding the prion protein has to be expressed, of course, but the same nucleotide sequence can express either the pathogenic or non-pathogenic conformation of the protein.

(5) Prions are described as 'non-Mendelian hereditary elements' because they self-propagate by transmitting their conformational characteristics in a lineage-forming manner, but do not form Mendelian patterns of inheritance (Liebman and Derkatch 1999).

(6) See HJ Muller $(1966,512)$ for an older view that the gene is a uniquely living material because of its capacity for reproduction, mutation and enzyme production.

(7) There are increasing reports of a variety of compartments in prokaryote cells and the rising use of 'organelle' to describe these structures (e.g., Niftrik et al. 2004; Seufferheld et al. 2003; Kerfeld et al. 2005; Komeili et al. 2006).

(8) Peroxisomes and Golgi bodies can sometimes be reconstituted from other membrane types (Cavalier-Smith 2000; Lowe and Barr 2007).

(9) Mitochondria were incorporated into early eukaryote cells before plastids. As well as primary plastids, obtained in a single endosymbiotic event, there are also secondary and tertiary plastids gained from endosymbioses of plastidcarrying organisms (Archibald 2007).

(10) Subsequent loss or dysfunction notwithstanding. See Embley and Martin (2006) for a demolition of the 'amitochondriate eukaryotes' hypothesis. 
(11) Single-stranded RNA viruses can be divided into positively and negatively stranded (sense and anti-sense) genomes, and retroviruses, which make DNA copies of themselves with their own reverse transcriptase before entering the host chromosome and being transcribed back to RNA (Ahlquist 2006).

(12) Viroids, which are tiny RNA viruses that infect plants, have no protein coat.

(13) While some other large viruses also carry translation and metabolic genes, Mimivirus greatly extends the known repertoire of these genes in viruses (Koonin 2005).

(14) Although see Moreira and López-Gárcia (2003) for the opposite claim.

(15) Inert Chlamydia 'spores' (elementary bodies) exist outside cells but the 'live' form of the organism conducts all its activities intracellularly. Note the parallels with the developmental cycle of viruses, which Chlamydia were once thought to be.

(16) However, Wolbachia in nematodes do provide host-related metabolic and other physiological functions (Fenn and Blaxter 2006). There is also increasing evidence of insect host benefits from Wolbachia infections (Iturbe-Ormaetxe and O’Neill 2007).

(17) Or from an endosymbiont with increasingly limited function to extinction. See Pérez-Brocal et al. (2006).

(18) All organisms have cell membranes, of course, but not the more rigid cell walls that plants and bacteria possess.

(19) There is increasing evidence, however, that Mycoplasma are also intracellular symbionts (e.g., Meseguer et al. 2003). And the genome of $\mathcal{N}$. equitans mentioned above is smaller than that of any mycoplasma.

(20) Mycoplasmas do, however, have multifunctional enzymes that have taken on unusual roles.

(21) See, however, Theodore Puck (1972) for an argument about the autonomy of mammalian cells.

(22) Abreu et al. (2007) assign the name Candidatus Magnetoglobus multicellularis to this organism ('Candidatus' indicates that it has not been cultured).

(23) Of course we accept the importance of membranes in the origins and maintenance of life in general, as well as the epistemological necessity of imposing boundaries for both theoretical and experimental biologists. This epistemic function does not, however, require that such boundaries be uniquely and unequivocally identifiable.

(24) The necessity of biochemical transformation rules out phenomena such as computer viruses as candidates for life, because they do not sustain themselves through biochemical means.

(25) Interactors thus conceived also rule out the whole planet as a candidate for evolving life, because although the planet could be conceived as metabolizing (in a highly collaborative way), it does not interact with other such wholes. It also lacks any means of reproducing itself. We are more ambivalent about ecosystems, which may frequently interact, but a case would have to be made for ecosystems forming a lineage that was more than mere continuity (as a substitute for replication).

(26) It is tempting here to invoke Kant's analysis of autonomy as the possibility of conformity to duty, an essentially socially defined concept, and his rejection of the notion of autonomy imagined as following no more than the pursuit of contingent individual interests or desires.

(27) Dynamic system-based scenarios of life are a general idea more precisely formulated in work by theoretical biologists such as Tibor Gánti, Robert Rosen, Stuart Kauffman, and Humberto Maturana and Francisco Varela. Our emphasis on collaborative interaction suggests congruences with this sort of work, but we have yet to explore these in any specific way. 


\section{AGKNOWLEDGMENTS}

We wish to thank Mark Bedau, the Egenis Philosophy of Biology Journal Club, our two anonymous referees and our editor for very constructive comments and advice. We found our second referee's summary of our paper especially helpful and incorporated it into a revised abstract. We also gratefully acknowledge funding from the the Economic and Social Research Council (UK). The research in this paper was part of the programme of the ESRC Centre for Genomics in Society (Egenis).

Copyright (C) 2009 Author(s).

This is an open-access article distributed under the terms of the Creative Commons Attribution-NonCommercial-NoDerivs license, which permits anyone to download, copy, distribute, or display the full text without asking for permission, provided that the creator(s) are given full credit, no derivative works are created, and the work is not used for commercial purposes.

ISSN 1949-0739 